\title{
Different methods for calculating Crop Water Stress Index using infrared thermography
}

\author{
Borjan Ranilović* \\ Alen Cukrov* \\ Ivanka Boras* \\ Srećko Švaic** \\ Monika Zovko** \\ * University of Zagreb, Faculty of Mechanical Engineering and Naval Architecture, Ivana Lučića 5, \\ Zagreb, Croatia \\ **University of Zagreb, Faculty of Agriculture, Svetošimunska cesta 25, Zagreb, Croatia
}

Key words: Infrared thermography, agriculture, CWSI

\begin{abstract}
:
When using infrared thermography in agriculture, the Crop Water Stress Index needs to be calculated. This requires the canopy temperature, as well as the dry and wet reference temperature, to be determined. In this paper, an overview of possible methods for their calculation and/or measurement is given, and an analysis which compares CWSI values obtained using different methods of determining the canopy temperatures, as well as different dry and wet reference temperatures, is presented. The effect of different methods on the statistical significance of the correlations found are presented and analyzed to determine the most promising method.
\end{abstract}

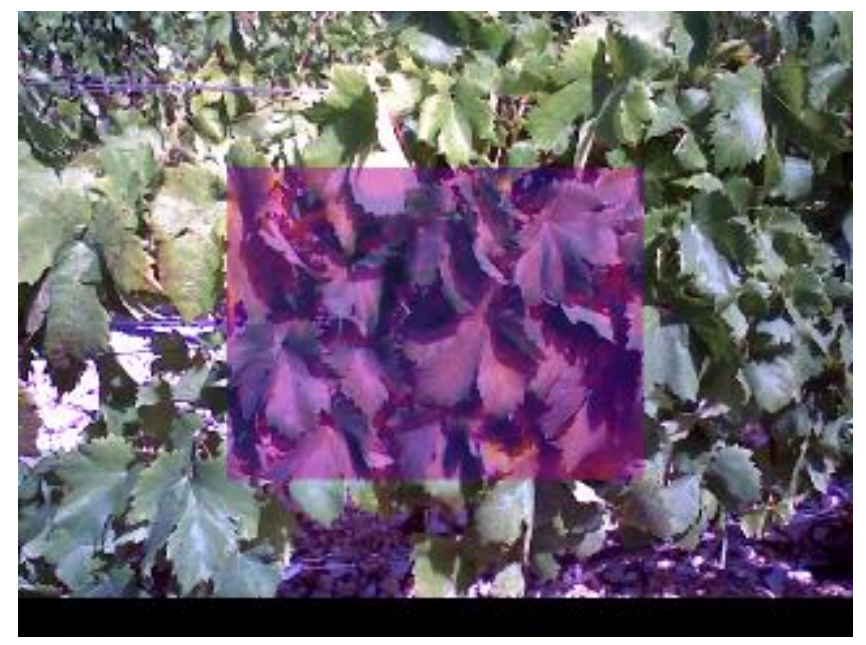

Figure 1 Photo and thermogram of selected grapevines 
10.21611/qirt.2020.123

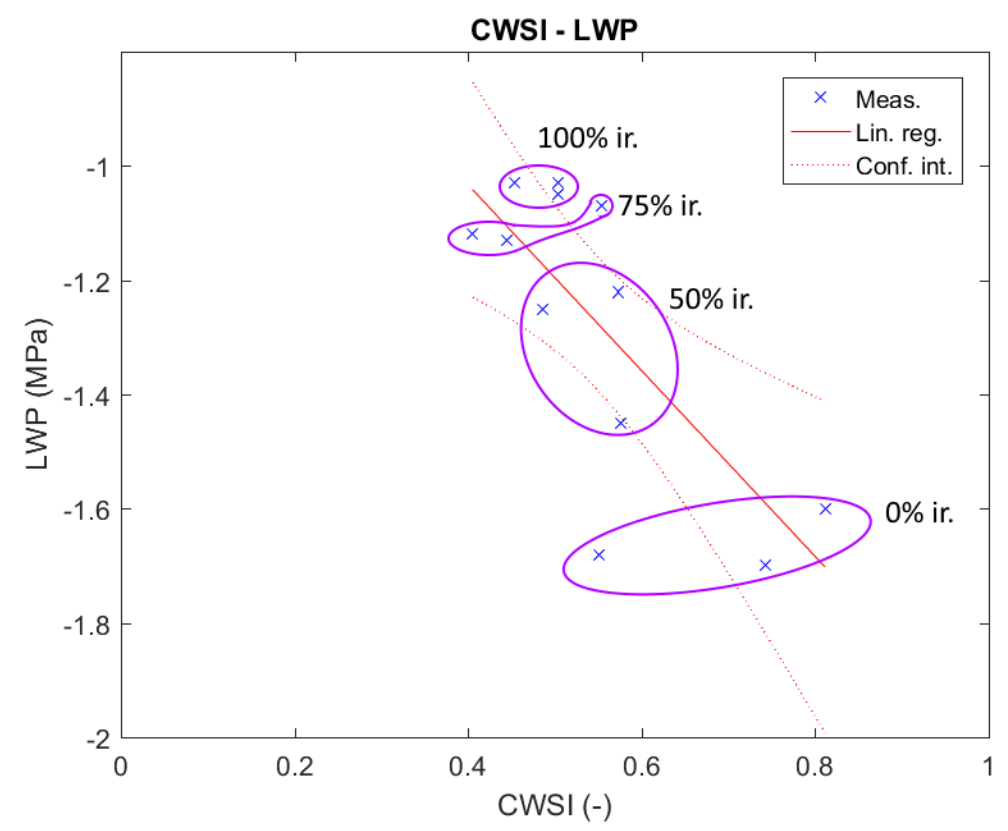

Figure 2 Results of CWSI-LWP analysis obtained for vineyard 